\title{
The Influence National Examinations on Classroom Practice in Primary Schools in Uganda: Case of Kampala and Kabale Districts
}

\author{
John Mary Vianney Mitana1, Anthony Mugagga Muwagga², Cornelius Ssempala ${ }^{3}$
}

\section{ARTICLE INFO}

Article History:

Received 31.12.2018

Received in revised form

27.04.2019

Accepted

Available online 01.07.2019

\begin{abstract}
Most classroom practices in developing countries are of an authoritarian nature and teacher-driven. Learners are rarely involved in the teaching and learning processes. Consequently, many of them complete school without learning enough of what they are expected to learn to optimally function in their respective societies. Studies have continuously blamed such a situation on the influence of national examinations. However, there is limited consensus on the magnitude and direction of such influence. This study, therefore, set out to explore the influence of public examinations on classroom practice. The study sample included 124 teachers, 540 pupils, 18 school administrators, 10 parents and 02 officials from the private assessment institutions (Uwezo and RTI) and one official from Uganda National Examination Board. The study reveals that teachers' selection of teaching methods is directly influenced by assessment, particularly public examinations. The methods used in teaching were those that encourage rote learning and memorisation of facts. Therefore, little or no effort is dedicated to teaching and learning methodologies that could foster the acquisition of high order thinking skills like critical thinking or problem-solving. The study argues that national examinations can be used to improved classroom practice if the content and methods of assessment are tuned to the educational objectives. The study recommends the inclusion of more test items with high order thinking skills in the Primary Leaving Examinations. This will motivate teachers and pupils to focus classroom practice on higher order thinking competencies instead of rote learning.
\end{abstract}

(c) IJERE. All rights reserved

Keywords: ${ }^{1}$ Examinations, primary leaving examinations, classroom practice, pedagogy, educational assessment in uganda, higher order thinking skills.

\section{INTRODUCTION}

Pedagogical practices, in most classrooms within low and middle-income countries, are described as authoritarian, rigid, formalistic, teacher-dominated and lecture-driven (Altinyelken, 2015). Student's activities are often limited to memorising and reciting facts and reproducing them for the teacher during examinations (Pontefract \& Hardman, 2005). Such pedagogical practices hardly nurture creative, imaginative, critical or problem-solving skills which learners require for life in and beyond school. In African, specifically in Uganda, such pedagogical practices have given rise to a phenomenon in which students who are successful in school do not have the skills and competences they require in life (Odongo, 2018). Enormous literature on assessment and examination has shown that the nature and quality of end of cycle examinations influence classroom practice (Ahmad \& Rao, 2012; Chapman \& Snyder, 2000; Snyder, 1997; Sukyadi \& Mardiani, 2011). Whereas literature agrees that assessment and examinations influence classroom practice, there is no agreement on the nature and magnitude of the influence. For example, whereas Ahmad and Rao (2012); Sukyadi and Mardiani, (2011) argue that end of cycle examinations have a negative backwash effect on classroom practice through examinations, Chapman and Snyder (2000); Snyder (1997) argue that the influence is neutral. The argument of a neutral influence of public examinations on classroom practice contends that examination "tendencies can also be used to encourage instructional reform - by intentionally changing national tests in ways that require teachers to change their teaching in order for their students to do well on these exams" (Chapman \& Snyder, 2000:460). Based on this argument of a neutral influence of public examinations on classroom practice, this article seeks to explore the influence of Primary Leaving Examinations (PLE) to classroom practice in Uganda.

\section{Study purpose}

The study aimed at exploring the influence of national examinations on classroom practice.

\footnotetext{
1 Principal, Luigi Giussani Institute of Higher Education , orcid.org/0000-0002-7553-7369; Researcher ID: D-9618-2018

2. Associate Professor, School of Education, College of Education and External Studies, Makerere University; orcid.org/0000-0001-7190-2819

3. Senior Lecturer, School of Education, College of Education and External Studies, Makerere University; orcid.org/0000-0002-1914-8350

Corresponding e-mail: mitanavianney@yahoo.com
} 


\section{Specific study objectives}

1. To explore the pedagogical methods used in primary schools in Uganda.

2. To explore why teachers in primary schools in Uganda choose to employ particular teaching methods.

3. To explain how end of cycle examinations influence the teaching and learning processes in primary schools in Uganda.

\section{Study Design}

The study adopted a qualitative case study paradigm to study the influence of end of cycle examinations on classroom practice. Following the argument of Creswell (2014) on the use of qualitative study designs, this study adopted the design because it enabled us to study the influence of end of cycle examinations in its natural setting. In this study the Primary Leaving Examinations (PLE) were taken as a case study within the context of Kabale and Kampala districts. The study was particularly interested in describing and documenting how Primary Leaving Examinations influence classroom practice within the Ugandan context, specifically in Kabale and Kampala districts. This study relied on the utilization of intuitive and felt knowledge of the teachers, pupils, parents, school leaders and government officials about PLE and classroom practice. This is because often the nuances of the multiple realities can be appreciated most in this way (Lincoln \& Guba, 1985).

A triangulation of data types and sources was used to enrich the study findings as advised by Creswell (2014). Four data types were used in this study were observations, interviews, documents and questionnaires. The data were collected from headteachers, teachers, pupils and parents. Document analysis (primary six and seven syllabi and question papers teachers' schemes of work and lesson plans) provided empirical evidence of the phenomenon; classroom observation guides were used to explore what exactly happens in the classroom during the teaching and learning process and how it relates to end of cycle examinations; the questionnaire was used for collecting preliminary quantitative data from teachers and pupils on how educational assessment influences classroom practice. Interviews were done with teachers, pupils and parents to explore in detail the issues raised in this study.

\section{Participants in the Study}

The study was conducted in Uganda in the districts of Kabale and Kampala. Eighteen primary schools participated. The targeted population included 18 headteachers, 124 classroom teachers, 540 pupils, 10 (four male, six female) parents, one (female) participant from Uganda National Examinations Board (UNEB), and two (female) participants from private organisations engaged in educational assessment at primary school level. Six (33\%) of the headteachers were female and $12(67 \%)$ were male. Of the 124 teachers who filled out a self-administered questionnaire, $74(59.7 \%)$ were female and $50(40.3 \%)$ were male. Of 540 completed and valid questionnaires from pupils, $250(46.3 \%)$ were from male participants and $290(53.7 \%)$ were from female participants. The pupil study participants were aged between 9 and 17 and were all in either primary six or seven. The rest of the study participants were 20 years and above. Parents, headteachers, teachers and pupils were selected from the 18 sampled primary schools in Kabale and Kampala districts while the rest of the study participants were selected from their respective institutions and by the fact of their institutional location, were drawn from Kampala district. Headteachers were included in the study because they hold the ultimate responsibility of the teaching and learning activities in a school. The headteachers enriched the study with their experience as supervisors of what happens in the classrooms - classroom practice in the schools. Classroom teachers were included in this study because they are the immediate custodians and facilitators of classroom practice. The inclusion of classroom teachers enriched then study with their experience on what influences their choice of methods and techniques in the classroom. Pupils were included in the study because they are the ultimate beneficiaries of classroom practices - they are consumers and co-creators of knowledge in the classroom. Thus, the inclusion of pupils in this study enriched the study with their learning experiences in the classrooms. Parents were included in the study because they are the indirect consumers of school outcomes. They make decisions concerning the type and quality of school their children go to. The inclusion of parents in the study enabled us to explore why parents choose schools; how their choices are linked to end of cycle examinations and how this linkage ultimately influences classroom practice. 


\section{Sampling Design and Techniques}

Onwuegbuzie and Leech (2007) define a sampling design as " a framework within which sampling occurs, comprising the numbers and types of sampling schemes and sample size" (p.239). Onwuegbuzie \& Leech (2007) continue to give three type of sampling frames used in qualitative studies: parallel smapling design, nested sampling design and multilevel sampling design. A parallel sampling design is used when there is need to make "credible comparisons of two or more different subgroups that are extracted from the same level of study" (Onwuegbuzie \& Leech, 2007, p. 239). The nested sampling design is used where "one or more members of the same sub-group represent a sub-sample of the full sample" while multilvel sampling design is used to "facilitate credible comparisons of two or more sub-groups that are extracted from different levels of study" (p.240). Based on Onwuegbuzie \& Leech's arguments, the study used both nested and multilevel sampling designs to come up with a meaningful sample of study participants. The nested sampling design was used to extract participants of the same sub-groups of teachers and pupils to participate in focus group discussions while the entire sub-groups participated in responding to the questionnaires. The multilevel sampling design was used, on the other hand, to extract sub-groups from different levels to participate in the study. For example, within each school, three sub-groups were selected: the head teachers, class teachers and pupils. This was meant to increase opportunities to compare the data got from different levels which could in term increase the levels of confidence in the data provided through crosschecking. Within the selected sampling designs, the study used purposive, convenience sampling techniques as explained below.

\section{Purposive Sampling}

Purposive sampling was used because it allows the researcher to study cases or subjects that have the required information which is relevant to the study objectives (Mugenda \& Mugenda, 2003). In this study, class teachers were handpicked because they were deemed informative about assessment in their respective schools. Class teachers oversee coordinating assessments and examinations at a classroom level. The researcher selected seven class teachers per school to participate in the study. A total of 126 teachers were selected to participate in the study.

The purposive sampling technique was also used in selecting the classes to participate in the study, head teachers and officials from UNEB, RTI international and Uwezo. The officials from UNEB, RTI International and Uwezo were purposively selected because of the richness of information they have accumulated over time from their profound experience in educational assessment in primary schools. The richness of the information gathered from the purposively selected participants improves the validity, usefulness and relevance of the knowledge generated from the current study and the possibility of a significant contribution to policy in educational assessment.

\section{Stratified Purposive Sampling}

Stratified purposive sampling is a sampling technique that combines both non-probability (purposive) and probability (random) sampling techniques (Teddlie \& Yu, 2007). The researcher used a four-stage stratified technique to select pupils to participate in the study. The first stage involved selection of the districts to participate in the study. Kampala and Kabale Districts were purposively selected to strengthen the cases under the study. The second stage involved the selection of the schools. Following the inclusion and exclusion criteria, nine primary schools per district were randomly selected. All registered primary schools with seven classes (primary one to primary seven), employing at least seven teachers excluding the head teacher and with a minimum pupils' population of 15 in each of primary six and primary seven were put in a sampling frame. While considering the above inclusion criteria, nine schools per district were then purposively selected to participate in the study. In this case convenience sampling was also applied to allow cases of willing schools participate in the study. The schools that denied access to the researcher were immediately replaced. However, caution was made to ensure that replacement was done with the schools of the same demographic characteristics.

The third sampling stage involved the selection of the classes to participate in the study. Pupils were stratified according to their classes and then Primary Six and Seven pupils were purposefully selected to participate in the study. These two classes were selected because of their relatively better English proficiency levels than the lower primary school classes and the consequent ability to answer questionnaires and participate in FGDs which were in the English language. This was further meant to increase the levels of 
validity of the study instruments and the usefulness of the study results. The final sampling stage involved the selection of pupils from the selected classes. Upon selecting primary six and primary seven classes, 15 pupils were selected per class using a systematic random sampling procedure.

\section{Convenience Sampling}

Convenience sampling technique is used in selecting cases for a study as they become available to the researcher (Mugenda \& Mugenda 2003). The advantage with convenience sampling is that it increases the willingness of the cases to participate in the study (Mugenda \& Mugenda 2003) and this in turn increases the participants' willingness to share information related to the study. To select the pupils, all pupils in the class where introduced to the study purpose and objectives and were requested to sign the assent forms. Although the study required only 15 pupils per class, in case of additional pupils willing to participate were allowed but at the analysis point only 15 pupils per class were selected. This enabled the researcher to replace pupils who could not complete the questionnaire due to language difficulties as it was evident in some schools. A total of 30 pupils per school were selected to participate in the study. In total, 540 pupils participated in the study.

\section{Data collection techniques and instruments}

The data collection techniques included surveys, interviews, observation and documentary analysis. The survey technique was used to collect general and preliminary information from 18 headteachers, 124 teachers and 540 pupils about the influence of Primary Leaving Examinations on classroom practice within the selected schools. Interviews were used obtain in-depth data from teachers, pupils and parents on the influence of Primary Leaving Examinations on classroom practice. Semi-structured interviews were done with each of the 18 headteachers, while ten one-on-one face to face interviews were done with 10 parents. A total of eight Focus Group Discussion (FGDs) were conducted - four with teacher and the other four with pupils. Each FGD had an average of six participants. Classroom observations were made to obtain first-hand information on what happens within the classrooms of the schools under the study. As argued by Ritchie (2003) in her work in qualitative research, classroom observation was found the best way of studying behaviour of participants (teachers and pupils) in their own setting. This enabled us to interpret the meaning teachers and pupils attached to assessment and examinations in the classroom. Finally, documentary analysis was done to understand the linkage between the documents teachers use on a regular basis and establish how these documents link with end of cycle examinations and how this linkage influences classroom practice. The documents analysed included the primary six curricula (National curriculum Development Centre (NCDC), 2010) and seven curricula (NCDC, 2012), teachers' schemes of work and lesson plans, sample examinations question papers teachers use for classroom based-assessment and PLE question papers (2010-2016).

\section{Data Managements and Analysis}

The questionnaire responses were entered pre-designed data templates using EpiData (version 3.1), which provides for validity checks during data capture. The data were then exported to statistical analysis software -SPSS (version 10) for merging, editing and cleaning, and eventual data analysis. Descriptive statistics were used to calculate simple frequencies, and percentages of participant responses. For qualitative data, the researcher identified themes and classified them according to the study objectives as well as keeping an open mind towards emerging themes, concepts, or categories. The data were indexed and then labelled so that parts of the data that referred to more than one theme or category were multi-indexed. The study uses the term "indexing" to establish how individual sections of data collected relate to study objectives - in this case, the study themes (Ritchie \& Spencer, 2003). The data were then sorted by theme, 
synthesized and presented in thematic charts so that key points of each piece of data was summarized for easy analysis. This involved detection, categorization, and classification of data for easy interpretation.

\section{Study Findings}

The study reveals dominancy of teacher-centred pedagogical approaches and techniques in the classrooms. In all the 10 classroom observations, it was evident that teachers merely narrated lesson contents to the pupils. The document analysis reveals that whereas teachers made schemes of work, most schemes of work lacked evidence of planning to use of learner-based methods of teaching. Further scrutiny of the schemes of work and the data gathered from interviews with teachers reveal that most teachers teach at best to the test aimed at maximising the chances of pupils to pupils to pass the final examinations and at work to merely complete the syllabus. In fact, the analysis of interview data reveal that whereas teachers are technically knowledgeable about usefulness of learn-centred methods towards improving learning outcomes, they still perceive such methods as a waste of time. Most of the teachers relied on reading lesson notes to the learners or writing on the board for the learners to copy. One of the interviewed teachers noted that "we rush through lesson notes because we are on pressure to complete the syllabus". This statement was supported by survey data which reveal that 111 (90.3\%) of the sampled teachers agreed to the idea that they are on social pressure to "produce" to complete the syllabus and produce examination grades.

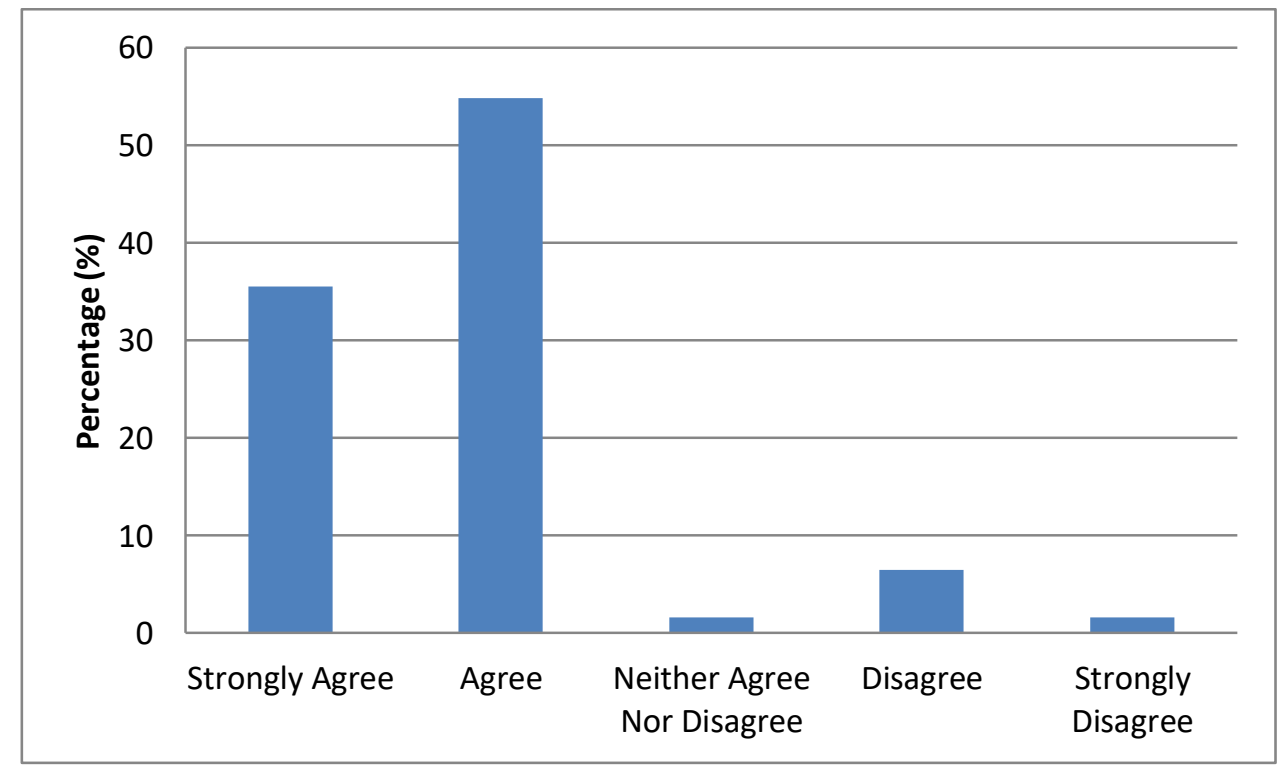

Figure 1: Social Pressure on Teachers

Apparently, the social pressure come from parents, school owners and at times from "strategic" supervisors of the schools including members of the School Management Committee (SMC) and or the local government. This was evidenced by one of the interviewed participants who noted that in our district, if the school does not score up to the required test scores, the headteacher is demoted or transferred to a more remote school.

The above phenomenon explains the prevalence teacher-centred methods in Ugandan primary schools. Further still, the study findings reveal teachers' perception of education is skewed towards end of cycle examinations. Teachers' responses on "why pupils mainly study" demonstrate a strong assumption that educational assessment is the driving force that makes pupils come to school. For example, 108 teachers (84.3\%) of the 124 sampled teachers reported that pupils study mainly to pass examinations (see Fig.2 below). Teachers assume that pupils come to school with a prime reason of passing examinations. The 
assumption of teachers about learners as persons searching for academic grades is also reported to be having salient implications on the way they handle pupils and what they do with them.

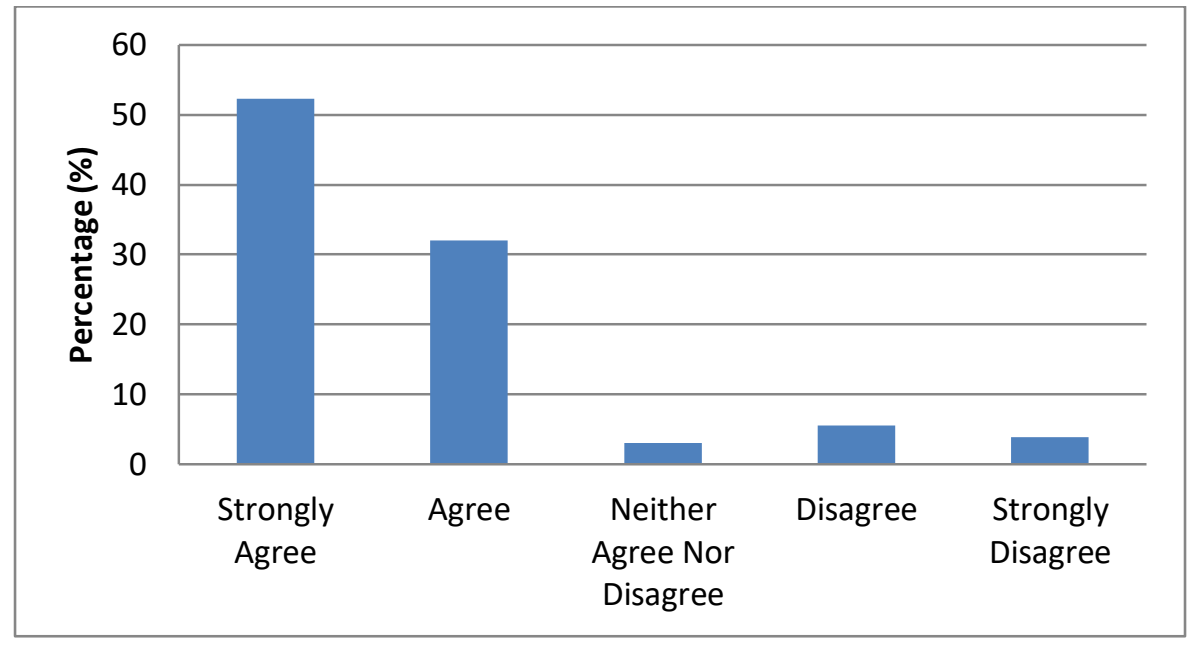

Figure 2: Teachers" Perception on Why pupils come to study

For instance, during the FGDs, it was revealed that teachers give pupils many exams and tests in a single academic term because they believe that regular tests prepare pupils to pass end of cycle examinations. During one of the FGDs, a teacher noted,

as teachers, we are forced to give constant tests and exams especially in primary seven because we want them to pass, although at times it leads to more assessment than teaching.

Further scrutiny of the teacher-responses about why they give excessive tests and exams in a single academic term revealed it was revealed that they are highly influenced by the end of cycle examination. For example, while $107(86.2 \%)$ of the sampled teachers agreed to the phenomenon of over assessment instead of teaching within the schools, $95(76.6 \%)$ of the sampled teachers noted that their major aim of giving so many tests is to predict the end of cycle examinations. In this case the end of cycle examinations greatly influence the teaching and learning processes. This means that as teachers focus on the final (end of cycle) examinations as the ultimate goal of teaching, it results into what is commonly known as the "Measurement Driven Instruction (MDI)" or the backwash effect. The MDI was more evident in the sampled schools whereby $75(60.5 \%)$ of the teachers said that the major reason they teach for pupils to pass the Primary Leaving Examinations.

However, not all is lost. As Chapman and Snyder (2000) have argued that the influence of end of cycle examinations on classroom practice is neutral, in this article we argue that teachers and institutions can strategically use MDI to improve classroom practice. If the content and process of end of cycle examinations change, teachers in schools are more likely to adjust their teaching methods and strategies so as to prepare pupils for such examinations. This is further supported by the study findings in which 463 (85.7\%) of the sampled pupils said that end of cycle examinations propel them to study hard. However, we argue that leaving the nature of Primary Leaving Examinations as currently they are, might not a positive influence on classroom practice. This is deduced for the analysis of the Primary Leaving Examinations questions (20102016) in which $86.8 \%$ of the examination items were categorised as Low Order Thinking skills (LOTs) questions and only $13.2 \%$ of the questions were categorised as High Order Thinking skills (HOTs) questions. Despite the end of cycle examinations focusing on Low Order Thinking skills, the analysis of primary six and seven syllabi reveals emphasis on High Order Thinking skills such as creative thinking, critical thinking and problem-solving. 


\section{Discussion}

The study findings agree with the previous studies such as Guloba, Wokadala and Bategeka (2010), Kagoda (2016), Mulumba, Onen, Musaazi, and Oonyu (2016) on teacher-centred methods. Ahmad and Rao (2012) argues that not only do end of cycle examinations influence teachers on how to teacher (teaching methodology) but also what to teach (the teaching content). These studies demonstrate that teachers tend to select the aspects/parts of curriculum that are highly expected to be examined and leave out those that are less expected. These studies have long demonstrated that when teachers focus on end of cycle examinations as the goal of teaching and learning in the classroom, they use teacher-centred pedagogical approaches. Abonyi (2014) argues that end of cycle examinations cause "Certification trauma" because certification often takes precedence over competence. Instead of focusing on developing learners' skills and competences, focus is often placed on passing the examinations in order to get a certificate. According to Abonyi, this situation is costly, especially to developing countries in a number of ways: leads to poor human development, unemployment, poverty and high levels of examination malpractices. The certification trauma is related to what Mitana, Muwagga, and Ssempala, (2019) have argued as the limiting factor towards teaching and assessment for successful intelligence in classrooms. Mitana and his colleagues argue that excessive focus on memory skills and knowledge which is easily retrieved during examinations often takes precedence over competences and skills which students require to navigate life. We therefore argue that when teachers and learners excessive focus on certification is detrimental to long-life learning and ability of learners to navigate life. Yet some authors such as Akcaalan (2016) argue that long-life learning is a key factor in being success both in school and beyond.

The study findings agree with the previous studies on backwash effects such as Boit, Njoki, and Changach (2012), Chapman and Snyder (2000) and Spratt (2005). This is agreement with the previous studies on Uganda Primary Leaving Examinations in which Snyder (1997) has argued that end of cycle examinations lead to "Measurement Driven Instruction (MDI)". These studies have demonstrated that teachers select their teaching methodologies based on what they expect from the end of cycle examinations. Spratt (2005) argues that end of cycle examinations influence how teachers interpret the curriculum, how they select the teaching materials and the teaching methods to employ. She further argues that end of cycle examinations tend to cause fear and anxiety among teachers and learners hence driving them to focus on the demands of the same examinations instead of the curriculum and other aspects of the education system. Chapman and Snyder (2000) have viewed this phenomenon as "Measurement Driven Instruction (MDI)". According to this view, schools, teachers and learners tend to focus their attention on teaching methodologies which are directly related to "what is measured" during exams as opposed to what is not. In this case, it is what is measured or examined which matters to the teacher and nit what is stated in the official curriculum.

The study findings agree with the study findings of Chapman and Snyder (2000) that end of cycle examinations greatly influence classroom practice. This is through the MDI or the backwash effect of examinations. In terms of nature of influence, Ahmad and Rao (2012) argue that end of cycle examinations can either have positive or negative influence on classroom practice. This means that end of cycle examinations can be used to improve classroom practice much as they can be detrimental to deep learning due to rote learning as the focus is placed on only what is examined. Chapman and Snyder (2000) and Spratt (2005) argue that if the content and process of end of cycle examinations change, teachers in schools are more likely to adjust their teaching methods and strategies so as to prepare pupils for such examinations. This means that examinations can strategically be used for educational reforms if well planned and implemented.

\subsection{Conclusions and Recommendations.}


Since most teachers are accustomed to the use of teacher-centred pedagogical methods, it is an uphill task to reverse the status quo. Most of the teachers are using the way the way they were taught starting from primary to the college level. They were taught to pass examinations and they are equally teaching pupils to pass examinations. We thus recommend the teacher training institutions to model the use of learner-centred pedagogical methods to interest the newly trained teachers and to demonstrate how learner-centred pedagogical methods work.

Teachers in Uganda primary schools choose pedagogical methods that easily and directly enable them to teach for end of cycle examinations. Thus, they teach to the test. Primary Leaving Examinations are thus a motivating factor many of the classroom practices. We thus recommend the introduction of continuous assessment to reduce the power and influence of a single-one-time examination. If this is done, teachers will prepare pupils for understanding instead of merely passing a one-time examination.

Since the influence of the end of cycle examinations on classroom practice is neutral, the content and processes of end of cycle examinations can be used to influence what happens in the classroom. We therefore recommend an increase of the number of examination items with high order thinking skills. This will motivate teachers to start teaching their pupils in a way that calls for high order thinking abilities instead of merely recall of information for final examinations. We recommend that this study becomes the starting point for the Uganda National Examinations Board (UNEB) to plan an improvement on preparation of test items that call for high order thinking.

\subsection{Limitations of the Study}

The study population comprised of primary schools in Kampala and Kabale Districts. Although these two districts have characteristics similar to urban and rural districts respectively in Uganda, some districts have unique characteristics and so these study findings may not be generalised to all districts in Uganda. These study findings should be read and interpreted within the Ugandan context and specifically Kampala and Kabale districts.

The researchers are aware of the central role of the National Curriculum Development Centre (NCDC) in the process of educational assessment. It the NCDC that drafts the blue print that UNEB uses to design test items for PLE. The researchers did not include any officials from NCDC among the study participants. However, to minimise this limitation, the study reviewed the respective curricular (primary six and seven) to get insights on the assessment context and general guidelines for assessment.

\section{References}

Abonyi, O. (2014). Evaluation and public examinations. National Conference of the Faculty of Education,. Nnamdi Azikwe University, Awka - Nigeria. doi:10.13140/RG.2.14665.0727

Ahmad, S., \& Rao, C. (2012). Examination washback effect: Syllabus, teaching methodology and the learners' communicative competences. Journal for Edaucation and Practice, 3(13).

Akcaalan, M. (2016). Investigating the relationship between lifelong learning and social emotional learning. International Journal of Educational Research Review, 14-20. Retrieved October 28, 2018

Allen, R., Elks, P., Outthred, R., \& Varly, P. (2016). Uganda's assessment system: A roadmap for enhancing assessment in education: An assessment report. Kampala.

Altinyelken, H. (2015). Education for All 2000-2015. Achievements and challenges. Washington DC: World Bank.

Boit, M., Njoki, A., \& Changach, J. (2012). The Influence of examinations on the stated curriculum goals. American International Journal of Contemporary Research, 2(2). Retrieved from http://www.aijcnet.com

Chapman, D., \& Snyder, C. (2000). Can high stakes examinations improve instruction: Re-examining Convensional wisdom. International Journal of Educational Development, 20, 457-474. 
Mitana,J.M.V., Muwagga,A.M. \& Ssempala,C.(2019). The influence national examinations on classroom practice in primary schools in Uganda: Case of Kampala and Kabale districts. International Journal of Educational Research Review,4(3),472-480.

Creswell, J. (2014). Research design: Qualitative, quantitative and mixed methods approaches. London: Sage Publications.

Greaney, V., \& Kellaghan, T. (2008). Assessing national achievement levels in education. Washington DC: The World Bank. doi:1596/978-0-8213-7258-6

Guloba, M., Wokadala, J., \& Bategeka, L. (2010). Does teaching methods and availability of teaching resources influence pupils' performance: Evidence from four districts in Uganda. Kampala: Economic Policy Research Centre (EPRC).

Kagoda, A. (2016). Teaching of geography in ugandabsecondary schools: Reflections of geography teacher trainees at the school of education, Makerere University, Uganda. Advances in Social Sciences Research Journal, 25-38. doi:10.14738/assrj.35.2016

Ministry of Education and Sports (MoES). (2017a). National symposium on assessment and examinations: Present and Future Prospects. Kampala: MoES.

Mitana, J., Muwagga, A., \& Ssempala, C. (2019). Assessment for successful intelligence: A paradigm shift in classroom practice. International Journal of Educational Research Review, 4(1), 106-115.

Mugenda, O. M., \& Mugenda, A. (2003). Resaerch methods: Quantitative and qualitative approaches. Nairobi, Kenya: African Centre for Technology Studies (ACTS) Press.

Mulumba, P., Onen, D., Musaazi, J., \& Oonyu, J. (2016). Instructional supervision and the pedagogical practices of secondary school teachers in Uganda. Journal of Education and Practice, 7(30), 177-187.

National curriculum Development Centre (NCDC). (2010). Primary six curriculum . Kampala: NCDC.

National Curriculum Development Centre (NCDC). (2012). Primary seven curriculum. Kampala: NCDC.

Odongo, D. N. (2018). Implications for sift-skills for national examinations in Uganda. 62nd Comparative and International Education Society (CIES) Conference. Mexico City: CIES.

Onwuegbuzie, A., \& Leech, N. (2007). Sampling designs in qualitative research: Making sampling process more public. The Qualitative Report, 238-254. Retrieved 12 19, 2018, from http://nsuworks.nova.edu/tqr/vol12.iss2/7

Pontefract, C., \& Hardman, F. (2005). The discourse of classroom intercation in Kenyan Primary Schools. Comparative Education, 41(1), 87-106.

Ritchie, J. (2003). The application of qualitative methods to social research. In J. Ritchie, \& J. Lewis, Qualitative Research Practice: A Guide for Social Sience Students and Researchers (pp. 24-46). London : Sage Publications.

Ritchie, J., \& Spencer, L. (2003). Carrying out qualitative analysis. In J. Ritchie, \& J. Lewis, Qualitative Research Practice: A Guide for Social Science Students and Researchers (pp. 221-263). London/Thousand Oaks/New Delhi: Sage Publications.

Snyder, C. (1997). Exam fervor and fever: Case studies of the influence of primary leaving examinations on Uganda classrooms, teachers and pupils. Academy for Educational Development .

Spratt, M. (2005). Washback and the classroom: The implications for teaching and learning of studies of washback from exams. Language Teaching Research, 9(1), 5-29.

Sukyadi, D., \& Mardiani, R. (2011). The effect of English national exam (ENE) on English teachers' Classroom teaching and learning. Kata, 13(1).

Teddlie, C., \& Yu, F. (2007). Mixed methods sampling: A typology with examples. Journal of Mixed Methods Research, 1(1). doi:10.1177/2345678906292430 